\title{
Congenital hydrocephalus in two pregnancies following the birth of a child with a neural tube defect: aetiology and management ${ }^{*}$
}

\author{
ROBERT D ROBERTSON†, DENNIS A SARTI+, W JANN BROWN§, AND \\ BARBARA F CRANDALL\|
}

From the Departments of $\dagger$ Obstetrics and Gynecology, $\ddagger$ Radiology, §Pathology, \|Pediatrics, and Psychiatry, UCLA Center for the Health Sciences, Los Angeles, California 90024, USA

SUMMARY A family is described with congenital hydrocephalus occurring in two pregnancies following the birth of a child with a neural tube defect (NTD). Prenatal diagnosis of hydrocephalus at mid-gestation was achieved by ultrasonography. The increased frequency of hydrocephalus among sibs of probands with a NTD and vice versa suggests that, following the birth of a child with either malformation, subsequent pregnancies should be monitored at mid-gestation by amniotic fluid AFP and serial ultrasound examination.

Hydrocephalus is a common major congenital malformation occurring in various populations with an incidence of 0.5 to 1.8 per 1000 births. $^{1}$ It is a malformation with both genetic and non-genetic factors involved in the pathogenesis. With the exception of the $\mathrm{X}$ linked form and that associated with spina bifida, hydrocephalus is usually sporadic, the overall recurrence risks being low. ${ }^{2}{ }^{3}$ Cohen et $a l^{4}$ have recently suggested an increased frequency of hydrocephalus among sibs of probands with a neural tube defect (NTD) and vice versa. This report describes congenital hydrocephalus in two pregnancies following the birth of a child with a NTD.

\section{Case reports}

A 34-year-old white female G5 P3 A2 was first seen at UCLA in 1975 following the delivery of a term male infant with an occipital encephalocele who died at 11 days of age (fig 1). Necropsy did not show cleft palate, polycystic kidneys, or external genital ambiguity that might have suggested Meckel syndrome. First trimester elective abortion had been performed in the previous pregnancy.

The third pregnancy was monitored by amniotic fluid $\alpha$-fetoprotein (AFP) and she delivered a normal male. Amniotic fluid AFP at mid-gestation was normal in the fourth pregnancy, but a stillborn

*Supported in part by HD-05615, Developmental Biology in Mental Retardation.

Received for publication 17 May 1980
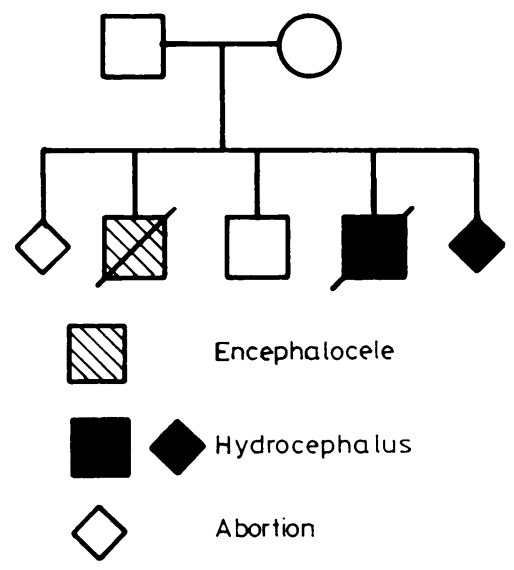

FIG 1 Family pedigree

male infant with hydrocephalus was delivered at term. Necropsy examination was limited by gross hydrocephalus and decompression to facilitate delivery but did not identify aqueductal stenosis. Microscopy did demonstrate aqueductal forking and thickening of the medullary vellum.

Amniocentesis and fetal ultrasound examination were performed in the 16 th week from the last menstrual period of the fifth pregnancy. The ultrasound study, amniotic fluid AFP, and chromosome analysis were normal and female. At 22 weeks' 


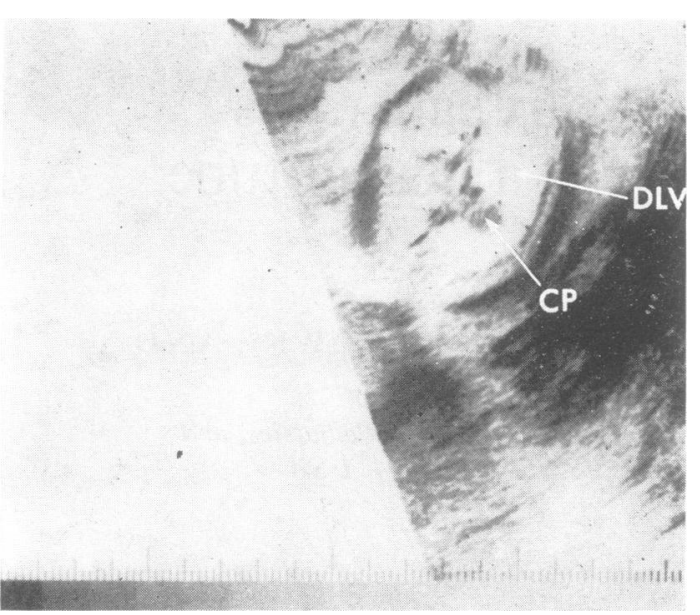

FIG 2 Transverse echogram of the fetal head at 22 weeks' gestation. An abnormal echo free area in one cerebral hemisphere containing a distinct echogenic mass is noted; this represents a dilated lateral ventricle ( $D L V)$ and corresponding choroid plexus $(C P)$. Failure to visualise the lateral ventricle in the other hemisphere is the result of ultrasound reverberation artefact arising from the proximal fetal skull and does not indicate a unilateral process.

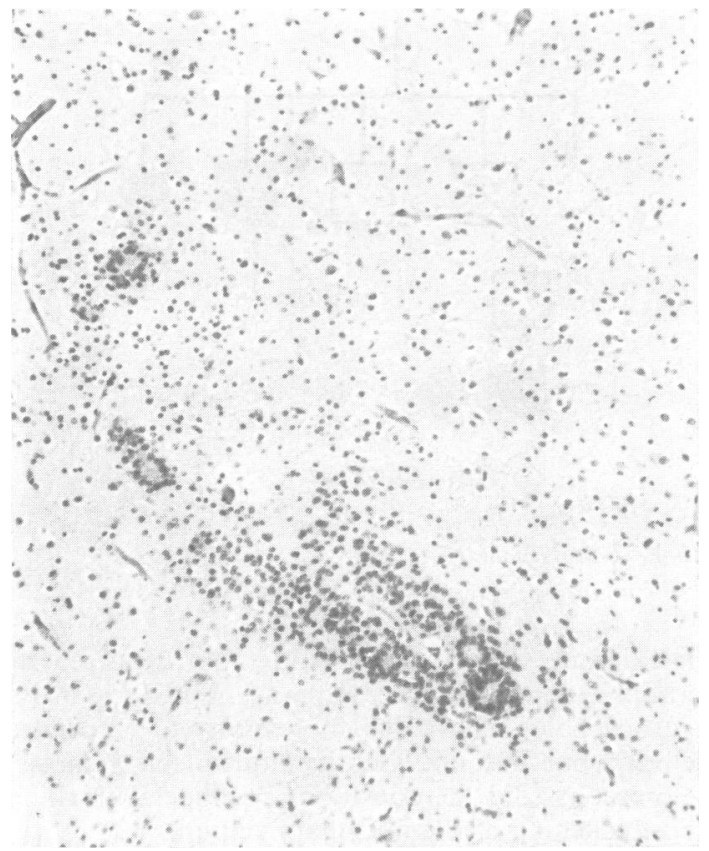

FIG 3 Segment of mesencephalon showing several ductules lined by ependymal cells which represent forking of the aqueduct. Note lack of astrocytic proliferation around these ductules. (Luxol Blue-PAS. Original magnification $\times 120$ ). gestation, a follow-up fetal ultrasound examination revealed the biparietal diameter (BPD) of the fetal head to be consistent with gestational age as assessed by dates and uterine size. However, a consistent abnormal echo free area in one cerebral hemisphere containing a distinct echogenic mass was noted (fig 2). Therapeutic abortion was performed and necropsy showed a female fetus with bilateral hydrocephalus. Microscopy demonstrated aqueductal forking and thickening of the medullary vellum (fig 3).

\section{Discussion}

The occurrence of congenital hydrocephalus in successive pregnancies is a rare event. Mehne ${ }^{5}$ reviewed the published reports of the last 500 years and found only 23 instances of successive pregnancies resulting in two or more children with hydrocephalus as the only anomaly. He reported one patient who delivered three successive hydrocephalic infants without other defects. Abdul-Karim et al ${ }^{6}$ reported two patients each with three consecutive hydrocephalic newborns and consanguinity in both families. Frohlich et $\mathrm{al}^{7}$ cited a patient with two successive hydrocephalic offspring.

Several modes of genetic transmission have been suggested for familial cases of hydrocephalus. It has been well established that aqueductal stenosis, the most common pathological type of hydrocephalus, ${ }^{8}$ may be inherited in an $\mathrm{X}$ linked recessive fashion, ${ }^{12910}$ although the proportion of males with aqueductal stenosis who have the $\mathrm{X}$ linked recessive type has not been established. $\mathrm{X}$ linked hydrocephalus may be the cause of $2 \%$ of all cases of isolated congenital hydrocephalus, ${ }^{11}$ but data to support this estimate have not been presented. Autosomal recessive inheritance has been an alternative explanation where there have been multiple sibs of both sexes affected and is suggested by two reports of consanguinity. ${ }^{6}$ Autosomal recessive inheritance cannot be excluded in our family. Forking of the aqueduct and thickening of the medullary vellum, as demonstrated by microscopy, are suggestive of an early developmental defect but fail to clarify the aetiology. Examination for these particular anomalies in other cases may help to subdivide an apparently heterogeneous group of disorders.

Cohen et $a^{4}{ }^{4}$ reviewed published reports of hydrocephalus in sibs of children with a NTD and conversely the occurrence of the latter malformation after the birth of a hydrocephalic proband. They demonstrated a two- to five-fold increase in the frequency of hydrocephalus $(0.21 \%)$ among sibs of NTD probands when compared to their stated general population frequencies $(0.04$ to $0.09 \%)$. In ᄀ స్ట ర్

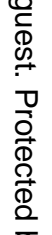
2 
addition, they found a two- to eight-fold increase of NTD $(1.6 \%)$ over population frequencies $(0 \cdot 2$ to $0.76 \%$ ), following the birth of a hydrocephalic child. They concluded that common aetiological factors may exist in both central nervous system malformations and proposed that amniotic fluid AFP assay is indicated in mothers of children with hydrocephalus.

Recent advances in diagnostic ultrasonography have made prenatal diagnosis of certain congenital malformations possible. Freeman et al ${ }^{12}$ successfully identified hydrocephalus in the second trimester by ultrasonography, noting a scant amount of amniotic fluid and a fetal head size larger than that predicted by the size of the uterus. Hydrocephalus was identified at 22 weeks' gestation in this case by a dilated lateral ventricle in the far hemisphere. Failure to visualise the lateral ventricle in the near hemisphere was the result of ultrasound reverberation artefact arising from the proximal fetal skull and did not indicate a unilateral process. The findings suggest that the diagnosis of hydrocephalus can be made before the fetal head becomes abnormally large, and would support the recommendation that serial ultrasound studies be performed, initially at the time of amniocentesis for AFP estimation and subsequently at 20 to 23 weeks' gestation. Limitations exist at present for the diagnosis of borderline cases suggesting that a more precise estimation should be made of the above changes. Measurement of the ratio of the maximal width of the lateral ventricle to the width of the ipsilateral hemisphere is currently being performed at weekly intervals in the second trimester of normal pregnancies to determine the upper limit of the normal range.

We recommend that following the birth of a child with either congenital hydrocephalus or a NTD, subsequent pregnancies be monitored at midgestation by amniotic fluid AFP and serial ultrasound examination.

\section{References}

1 Shannon MW, Nadler HL. X-linked hydrocephalus. J Med Genet 1968;5:326-8.

2 Edwards JH, Normal RM, Roberts JM. Sex-linked hydrocephalus: report of a family with 15 affected members. Arch Dis Child $1961 ; 36: 481-5$.

3 Burton BK. Recurrence risks for congenital hydrocephalus. Clin Genet 1979;16:47-53.

4 Cohen T, Stern E, Rosenmann A. Sib risk of neural tube defect: is prenatal diagnosis indicated in pregnancies following the birth of a hydrocephalic child? J Med Genet 1979;16:14-6.

5 Mehne RG. Three hydrocephalic newborns-each of a successive pregnancy of a white female. Arch Pediatr $1961 ; 78: 67-71$.

6 Abdul-Karim R, Iliya F, Iskandar G. Consecutive hydrocephalus. Obstet Gynecol 1964;24:376-8.

7 Frohlich GS, Starzer KL, Tortora JM. Successive hydrocephalic newborns. NY State J Med 1976;76:975-6.

8 McMillan PJ, Williams B. Aqueductal stenosis: case review and discussion. $J$ Neurol Neurosurg Psychiatry 1977;40:521-32.

9 Bickers DS, Adams RD. Hereditary stenosis of the aqueduct of Sylvius as a cause of congenital hydrocephalus. Brain 1949;72:246-62.

10 Holmes LB, Nash A, Zukhein GM, Levin M, Opitz JM. $\mathrm{X}$-linked aqueductal stenosis: clinical and neuropathological findings in two families. Pediatrics 1973;51:697704.

11 Editorial. Sex-linked hydrocephalus with severe mental defect. Br Med J 1962;i:168.

12 Freeman RK, McQuown DS, Secrist LJ, Larson EJ. The diagnosis of fetal hydrocephalus before viability. Obstet Gynecol 1977;49:109-12.

Requests for reprints to Dr Robert D Robertson, Department of Obstetrics and Gynecology, UCLA Center for the Health Sciences, Los Angeles, California 90024, USA 